\title{
NEGATIVE STAIN TRANSMISSION ELECTRON MICROSCOPY OF VIRUSES AND VIRUS-LIKE PARTICLES
}

\author{
C. D. Humphrey
}

Infectious Disease Pathology Branch, Division of Viral and Rickettsial Diseases, National Center for Zoonotic, Vector-Borne, and Enteric Diseases, Coordinating Center for Infectious Diseases, CDC, Atlanta, GA 30333

Negative stain transmission electron microscopy (NS-TEM) is a powerful tool for identifying pathogens both directly in body fluids (Fig. 1), and indirectly after successful culture (Fig. 2). Negative stain electron microscopy is also important for monitoring cell-culture adapted viruses and recombinant virus-like particles (VLPs) that are produced for biological and pharmaceutical purposes.

Cell-culture adapted viruses and VLPs are produced to make diagnostic immunoassay reagents, vaccines, pharmacological vectors, or biological control agents. They also may be used for basic studies of virus structure and formation. Monitoring structural character and purity is crucial to their successful use. Quality of viruses and VLPs cannot always be determined by visual interpretation of protein band locations after gradient centrifugation or gel electrophoresis. Electron microscopy (EM) including scanning EM, transmission EM (TEM), and scanning probe microscopy may also be used to assess the quality of virus/VLP production and purification. TEM processing may include vitreous ice embedding, chemical fixation-plastic embedding and thin-section, or negative staining as preparation for EM. NS-TEM of viruses and VLPs is performed routinely within our laboratory for quality/quantity assessment. Evaluations are done for preparation purity, particle structural quality, and quantity. Examples of viruses and VLPs we have tested in the past are listed below; some of which will be presented in more detail.

\section{Conventional Culture}

Arenavirus (Fig. 2)

Bacteriophage: biological control agents; (Figs. 4-6)

West Nile virus

Coronaviruses: SARS CoV, HCoV-43, HCoV-229E

and others

Paramyxovirus: Mumps, Parainfluenzavirus 1, 2

Metapneumovirus

Adenovirus: various types

Coxsackievirus: various types

Enterovirus: various types

Rotavirus A

Hepatitis A, B, E viruses

Influenzaviruses A, B

Mimivirus

\section{Recombinant VLPs}

Rotavirus C (Fig. 3)

Rotavirus B

West Nile virus

Western Equine Encephalitis virus

Papillomavirus 8

Papillomavirus 11

Papillomavirus 16

Sapporovirus

Norovirus

Hepatitis E virus

Human Bocavirus 

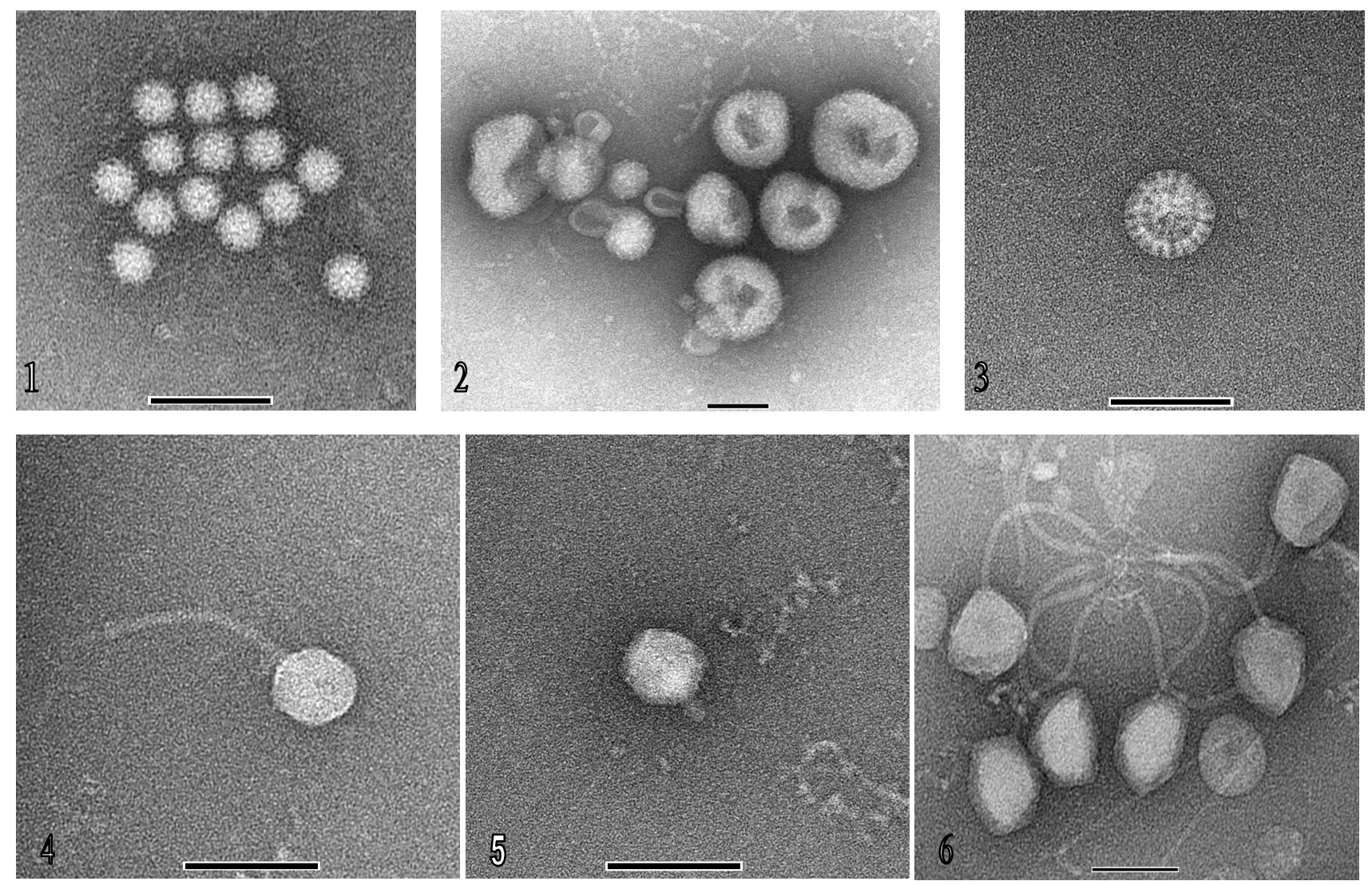

FIG. 1 Norovirus aggregate observed in human stool. Bar $=100 \mathrm{~nm}$. FIG. 2 "Old World" arenavirus grown in cell culture. Bar $=100 \mathrm{~nm}$.

FIG. 3 Rotavirus C recombinant VLP formed by combination of virus protein 6 and virus protein 7. $\mathrm{Bar}=100 \mathrm{~nm}$.

FIG. 4. Siphoviridae bacteriophage; a potential biological control agent against Pseudomonas aeruginosa. $\mathrm{Bar}=100 \mathrm{~nm}$.

FIG. 5. Podaviridae bacteriophage; a potential biological control agent against Pseudomonas aeruginosa. $\mathrm{Bar}=100 \mathrm{~nm}$.

FIG. 6 Siphoviridae bacteriophage; a potential biological control agent against Proteus mirabilis. Bar $=100 \mathrm{~nm}$.

Acknowledgements:

Personnel within Scientific Resources; Gastroenteritis and Respiratory Viruses Laboratory Branch, Division of Viral Diseases, NCIRD; Laboratory Branch, Viral Hepatitis Division, NCHHSTP; Special Pathogens Branch, Division of Viral and Rickettsial Diseases, NCZVED; Biofilm Laboratory, Clinical and Environmental Microbiology Branch, Division of Healthcare Quality Program; all of which are within US Centers for Disease Control and Prevention.

The majority of specimens to be discussed within the presentation were provided by Baoming Jiang, Kristina Bargeron, Jan Vinje, Dean Erdman, Teresa Peret, Theresa Cromeans, Rodney Donlan, Susan Lehman, and Laura Rose. Special acknowledgement is made to Maureen Metcalfe for her technical assistance. 